\title{
Surface Integrity Analysis in Machining of Hardened AISI 4140 Steel
}

\author{
Marco Antonio Stipkovic ${ }^{a, b}$, Éd Claudio Bordinassi ${ }^{a, b}$, Adalto de Farias ${ }^{a, b}$, Sergio Delijaicov ${ }^{a, *} *$ \\ ${ }^{a}$ Centro Universitário da FEI, Av. Humberto de Alencar Castelo Branco, 3972 - 09580.901, São \\ Bernardo do Campo, SP, Brazil

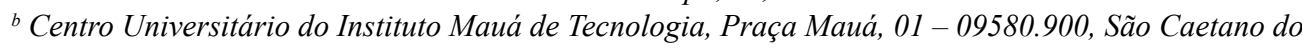 \\ Sul, SP, Brazil
}

Received: June 01, 2016; Revised: October 25, 2016; Accepted: December 27, 2016

\begin{abstract}
This study aimed to analyze the residual stresses and roughness in finishing milling of AISI 4140 steel, quenched and tempered up to hardness of $58 \mathrm{HRC}$. Machining operations were performed with the use of CBN inserts and by varying three basic cutting parameters (cutting speed, feed per tooth and cutting depth). Hardened materials are typically machined by abrasive processes, which in turn are more expensive and complex to be studied due to the undefined cutting geometry of the grinding wheel. A series of machining tests with milling process and CBN tools was implemented in order to study the resultant condition of the specimen's surface. An experimental design was used and the results were statistically treated, enabling the generation of a model that aims to obtain roughness values due to the optimization of three adopted cutting parameters. The roughness values found in the range of $\mathrm{R}_{\mathrm{a}} 0,16$ to $0,4 \mu \mathrm{m}$ indicate that it is possible to use the milling process with CBN tools for finishing, reducing machining time and the cost of the machined part. The generated residual stresses were compressive and the feed per tooth parameter showed greater influence in this result. The research was limited to test only one type of $\mathrm{CBN}$ insert, which was constantly replaced, preventing the influence of tool wear on responses. The geometry of the tool as well as the use of cutting fluid were not considered. Milling process with CBN inserts is confirmed as a possibility for replacing grinding process for finishing machining leading to significant gains in machining time. An optimized model was derived to predict the value of the roughness and three optimizations were made to specify the best cutting parameters to desirable answers such as better roughness, higher compressive residual stresses and low cutting forces, for example.
\end{abstract}

Keywords: Finishing milling, Roughness, Residual stress, AISI 4140 Hardened

\section{Introduction}

Mechanical, physical, chemical, and thermal effects generated by machining processes can modify the surface condition of a component, leading to different characteristics from those found in its core, affecting the component performance when subjected to working conditions ${ }^{1}$. For instance, rough surfaces produce greater thermal and electrical resistance than flat surfaces.

Due to the importance of the surface condition of machined parts, several researchers decided to study the characteristics of machined surfaces by analyzing the roughness and their chemical and mechanical properties, classifying this type of study as Surface Integrity (SI). In addition, the setting of process parameters, owing to its direct and/or indirect influences, defines the surface finish ${ }^{2}$.

The definition of surface integrity (SI) according to Field and Kahles ${ }^{3}$ is the inherent condition of a surface produced by a machining process or any other process of surface generation that could be evaluated by mechanical, metallurgical, chemical and topological properties of the

*e-mail: sergiode@fei.edu.br manufactured surface. Griffiths ${ }^{4}$ enhanced this definition relating the features mentioned in the operational performance of the component. These conditions are measured by varying the hardness, residual stress, surface roughness and structural corrosion resistance.

After the machining process, a microscopic examination of the surface usually presents different layers of thickness, of different compositions and mechanical behavior, usually resulting from plastic deformation and hardening.

Surfaces, which are characterized as a low quality surface integrity could be a result of different defects from combination of the manufacturing process, material problems and the possible lack of parameters process control, which can originate high temperatures and high stress levels. Many researchers ${ }^{1,5}$ classified the major surface defects such as: a) cracks or microcracks, b) craters, shallow depressions, which may be the result of chemical or physical attacks, c) folds often caused by overlapping material during machining, d) thermally affected zones, some of the material subjected to thermal cycles without fusion, e) inclusions, non-metallic elements embedded in metal castings, f) intergranular attack, weakening the grain boundary by fragilization and corrosion 
by the liquid metal, g) metallurgical transformation including phase transformations, re-solidification, decarburization, h) plastic deformation caused by high stresses generated by friction, geometry, and temperature of the tool or the process method, i) surface residual stresses of compression or traction, usually caused by non-uniform deformation or different temperature distributions.

According to Mia and Dhar ${ }^{6}$ steel is the highest used material for production of mechanical parts around the world. Recent researches in material, cutting tool technology and increased exploration for better performance leads to the use of hardened steels having hardness value of 40-65 HRC. According to Smith et al. ${ }^{7}$, the fatigue life of a AISI 52100 hardened steel component (60-62HRC), is strongly influenced by the roughness surface, when machined by super-finishing process $\left(\mathrm{R}_{\mathrm{a}} 0,1 \mu \mathrm{m}\right)$, showed an increase in the number of cycles of approximately $470 \%$ (from 56,867 to 323,897 cycles) compared to $\mathrm{R}_{\mathrm{a}} 0,66 \mu \mathrm{m}$ machined surfaces.

Residual stresses results from non-uniform deformation processes occurring during one or more stages of the manufacturing process of a component. When exclusively related to machining processes, residual stresses are produced as a result of heterogeneous plastic deformation induced by thermal and mechanical events associated with the process of chip formation. Plastic deformation resulting from forces parallel and perpendicular to the machined surface produces compressive residual stresses, while the plastic deformation, due to the localized heating, displaces the balance, causing tensile residual stresses ${ }^{8}$. Phase transformations help support the development of tensile and compressive residual stresses, depending on the relative variation of the volume and breakdown of plastic deformation 9 .

According to $\mathrm{Lu}^{10}$, the entire system of residual stresses is in balance, thus the sum of the resultant forces and moments produced is zero and the maximum value in module that residual stresses can reach is the actual yield strength of the material.

Residual stresses can be described in three types ${ }^{11,12}$ :

a) Residual stresses of the first type, also called macro-or macroscopic residual stresses. They are present in various grains and in a large area of the component. They are typically derived from mechanical, thermal or chemical sources and are of great interest of engineering standpoint because they may impact the service life of a component.

b) Residual stresses type 2, also called microstructural stresses, which are present in a grain or a part of it, and are caused by microscopic plastic deformations.

c) Residual stresses type 3, called micro stresses, are present in small interatomic distances contained in a small region of the grain caused by crystalline defects such as dislocations

Also according to Soares ${ }^{11}$, the residual micro stress type two and three, cannot be avoided in polycrystalline materials, and are more important to study the microstructural behavior. They can be induced by heat treatment, resulting from volume changes occurred by phase transformations, precipitation reactions or thermal deformation occurred due to the difference between the thermal expansion coefficients of a particle nonmetallic and metallic matrix during cooling.

Much research has been conducted to characterize the surface integrity of various materials, worked under different processes and machining conditions.

Jawahir at al. ${ }^{13}$ described the recent advances in the field, including theoretical and experimental aspects. Results for turning, milling, EDM and grinding were shown and analyzed as well as the correlations between process parameters and measurements of surface integrity. One of the key research point described by the authors is the development of predictive models to correlate the set of parameters of the surface integrity to the functional performance of machined components.

Da Silva et al. ${ }^{14}$ studied the effect of minimum quantity lubricant (MQL) on the surface integrity of AISI 4340 steel, quenched and tempered in cylindrical grinding operations using aluminum oxide grinding wheel. The results were promising in comparison with the conventional grinding and dry lubrication, resulting in lower values of roughness and higher values of compressive residual stresses.

Mhamdi et al. ${ }^{15}$ studied the influence of the position of the tool and the feed per tooth for the 3D roughness, micro-hardness and change in microstructure of titanium alloy Ti-6Al-4V during concave surface machining using a spherical end mill. The results showed better finish on upward and downward movement compared to machining on top.

Umbrello et al. ${ }^{16}$ and Pusavec et al. ${ }^{17}$ conducted studies on surface integrity of AISI 52100 hardened steel and Inconel alloy 718 in turning with $\mathrm{CBN}$ tool at cryogenic refrigeration conditions. In general, the surface integrity parameters such as roughness, residual stresses and white layer thickness were improved compared to dry machining, leading to better performance and life of the machined product.

In turn, Kloche et al. ${ }^{18}$ have contributed to the analysis of the effect of temperature in the cutting zone in the parameters of the surface integrity on broaching operations. The results allowed correlating the temperature values to the parameters of surface integrity (strength and micro-hardness).

Another interesting approach was conducted by Wei et $\mathrm{al}^{19}$, who focused their studies on developing relationships between process conditions, surface integrity and fatigue life of the component on dry milling operations. The results led to obtain fatigue lives greater than $10^{6}$ cycles or more due to the synergy effects of hardening and compressive residual stresses.

Mial and Dhar, ${ }^{6}$ executed optimizations of surface roughness and cutting temperature in hard turning. They tested AISI 1060 material in three different hardness conditions. The machining was done in dry condition and with high-pressure coolant to identify any improvement in surface roughness 
and also in temperature decrease. Using Taguchi method, they were able to found optimum conditions to the applied cases. They concluded that the application of HPC improves machinability of hardened steels as they observed a reduction of surface roughness in $12.9 \%$ and cutting temperature in $10.8 \%{ }^{6}$ when compared to dry cutting.

One of the aims for this study is to analyze the residual stresses after finishing milling of AISI 4140 steel quenched and tempered and to evaluate the most significant process parameters that correlated to it. Dry machining operations were performed with the use of $\mathrm{CBN}$ inserts in order to obtain optimal conditions to evaluate the resultant surface conditions of average roughness. Hardened materials are typically machined by abrasive processes, which in turn are more expensive and complex to be studied due to the undefined cutting geometry of the grinding wheel. Despite the cost of CBN inserts, machining processes with conventional machines and conventional tools geometries are simple than grinding process and may be an important alternative.

\section{Methods and materials}

The material studied was a forged AISI 4140 steel, surface hardened by quenching with depth of $3 \pm 1 \mathrm{~mm}$ and tempered to $58 \pm 2 \mathrm{HRC}$, with the chemical composition attested by performed test according to Table 1 . The specimens had rectangular geometry, measuring $140 \times 110 \times 20 \mathrm{~mm}$ with 2 holes to be fixed with hexagon socket head screw. Before each test the specimen was regularized by a roughing pass to avoid misalignment and changes in the test parameters. In Figure 1 is possible to verify the complete setup assemble used for the milling experiments, the axes directions were maintened for the residual stress measuring in order to correlate it with the correct machining conditions.

A central composite design (CCD) experimental planning was developed with 6 replicates at the central point, which generated the tests according to Table 2 .

The milling tool used had diameter of $63 \mathrm{~mm}$ and 5 tooth geometry, with all the diameter in contact to the specimen (code R245-063Q22-12M 260642), the CBN insert code was R245 12 T3 E CB50 both milling head and insert supplied by Sandvik company.

The milling machine used was a Sanches Blanes model FU-1, ISO 40, with maximum speed of $6000 \mathrm{rpm}$ and $\mathrm{V}_{\text {fmax }}$ $=1500 \mathrm{~mm} / \mathrm{min}$.

For the surface roughness analysis a portable Mitutoyo SJ-301 model was used, the parameter "cut-off" was adjusted to $0,8 \mathrm{~mm}$. For each measured surface, the roughness adopted was an arithmetic average $\left(\mathrm{R}_{\mathrm{a}}\right)$ established by three consecutive readings.
The residual stresses were measured from the surface of the workpiece to a depth of $0,4 \mathrm{~mm}$. It was decided to use the measuring blind hole method. The choosen equipment consists of a pneumatic milling machine, coupled to a micro strain gauge that transmits the data to a computer, recorded through H-Drill software, according to the system shown in Figure 2. The technical data of the equipment are: a) manufacturer: Sint Technology / Italy; b) Model: RESTAN; c) maximum speed: $400.000 \mathrm{rpm}$; d) maximum diameter of the drill: 2,2 mm; e) Air pressure: 3,5-5 bar; f) minimum vertical feed: intervals of 10 micrometers. The specimens were instrumented with rosettes type M062.

To evaluate white layer formation on the machined surfaces, it was used an optical microscope with amplification up to 1000x manufactured by Olympus Model GX-51, equipped with software and a monitor Sony Stream 46".

\section{Results and discussion}

Different from hard turning conditions ${ }^{6}$ where the thermal condition is favorable due to not present floating conditions, milling machining is very severe. In milling the tool/part contact is intermittent leading to a thermal floating condition. Therefore, the tests were performed with no process coolant (dry machining). The use of CBN inserts and the inherent thermal floating condition are not compatible. To minimize the tool damage due to thermal fatigue, dry machining is recommended in general for most situations where CBN insert is applied.

The values obtained in the surface roughness represent the average of three measurements taken in the central region of each specimen in the parallel direction to the adopted feed per tooth in the machining process.

The surface roughness values found in the the various tests revealed an appropriate roughness for finish machining processes ranging from 0,16 to $0,41 \mathrm{R}_{\mathrm{a}} \mu \mathrm{m}$. Figure 3 shows through the Pareto Diagram, that the surface roughness was influenced by 2 out of 3 cutting parameters studied, and the most representative was the feed per tooth $\left(f_{z}\right)$ followed by the cutting depth $\left(\mathrm{a}_{\mathrm{p}}\right)$.

Analyzing the results, it is clear that there is a direct relationship between feed per tooth and the roughness, that means, low roughness are obtained with small feed per tooths and high roughnesss with high feed per tooths. These results are in according to geometrical relationship and studies conducted by Mia et al. ${ }^{20}$. The finding that greater feed per tooths affect the surface finish of the workpiece is aligned with the current process of machining by milling because large feed per tooth combined with tools for small contact area can lead to the generation of ripples on the surface, worsening roughness.

Table 1. AISI 4140 Chemical compostion

\begin{tabular}{lcccccccccccc}
\hline $\mathrm{C}$ & $\mathrm{Mn}$ & $\mathrm{Si}$ & $\mathrm{P}$ & $\mathrm{S}$ & $\mathrm{Cr}$ & $\mathrm{Ni}$ & $\mathrm{Mo}$ & $\mathrm{Al}$ & $\mathrm{Cu}$ & $\mathrm{Ti}$ & $\mathrm{V}$ \\
\hline 0.413 & 0.842 & 0.241 & 0.013 & 0.012 & 0.904 & 0.045 & 0.181 & 0.030 & 0.063 & 0.002 & 0.004 \\
\hline
\end{tabular}




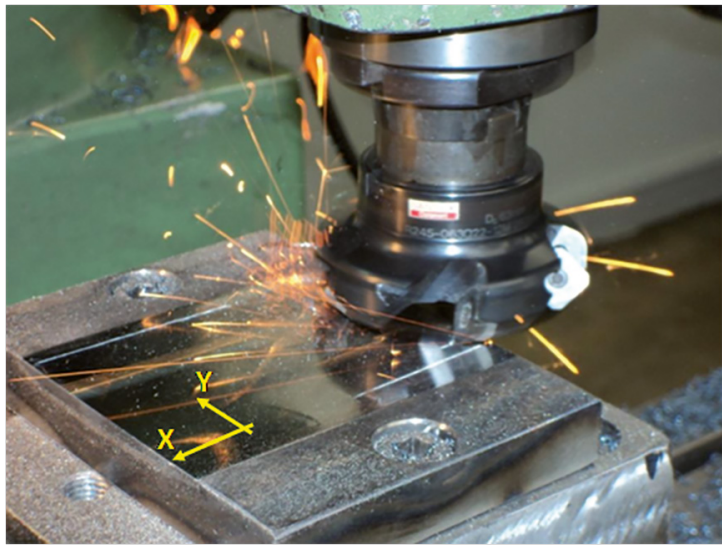

Figure 1. Setup assemble showing the axes configuration used for the residual stresses tests.

Table 2. Cutting parameters and experimental design

\begin{tabular}{|c|c|c|c|}
\hline Test & $\mathrm{v}_{\mathrm{c}}[\mathrm{m} / \mathrm{min}]$ & $\mathrm{f}_{\mathrm{z}}[\mathrm{mm} /$ tooth $]$ & $\mathrm{a}_{\mathrm{p}}[\mathrm{mm}]$ \\
\hline 1 & 150 & 0,05 & 0,1 \\
\hline 2 & 150 & 0,05 & 0,2 \\
\hline 3 & 150 & 0,15 & 0,1 \\
\hline 4 & 150 & 0,15 & 0,2 \\
\hline 5 & 300 & 0,05 & 0,1 \\
\hline 6 & 300 & 0,05 & 0,2 \\
\hline 7 & 300 & 0,15 & 0,1 \\
\hline 8 & 300 & 0,15 & 0,2 \\
\hline 9 & 98,9 & 0,1 & 0,15 \\
\hline 10 & 351,1 & 0,1 & 0,15 \\
\hline 11 & 225 & 0,016 & 0,15 \\
\hline 12 & 225 & 0,187 & 0,15 \\
\hline 13 & 225 & 0,1 & 0,07 \\
\hline 14 & 225 & 0,1 & 0,23 \\
\hline $15^{\circ}$ & 225 & 0,1 & 0,15 \\
\hline $16^{\circ}$ & 225 & 0,1 & 0,15 \\
\hline $17^{\circ}$ & 225 & 0,1 & 0,15 \\
\hline $18^{\circ}$ & 225 & 0,1 & 0,15 \\
\hline $19^{\circ}$ & 225 & 0,1 & 0,15 \\
\hline $20^{\circ}$ & 225 & 0,1 & 0,15 \\
\hline
\end{tabular}

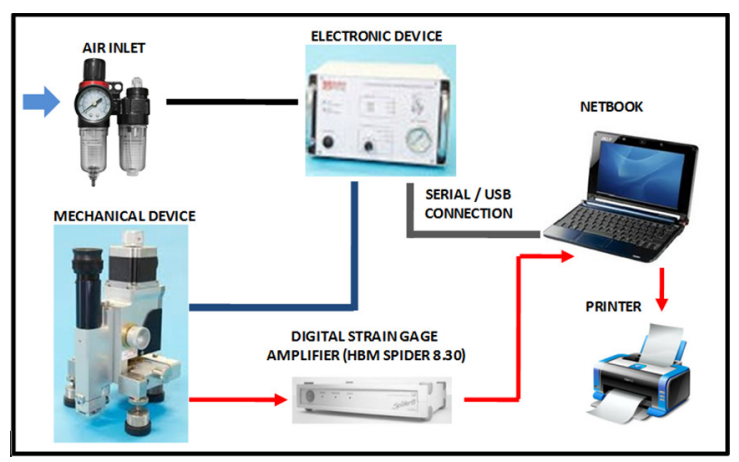

Figure 2. Schematic of the integrated system for measuring residual stress by blind hole technique applied

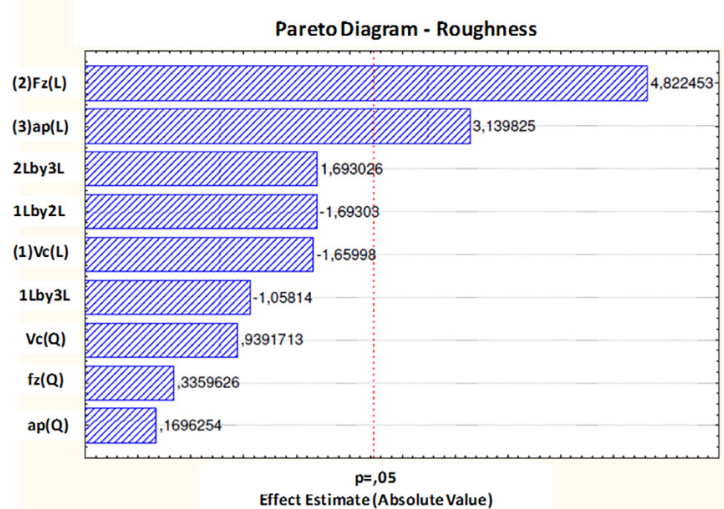

Figure 3. Pareto diagram of the influence of cutting parameters in the roughness

About the behavior of the cutting depth in the worsening of the roughness, as a direct result of the adoption of higher cutting depths, it is related to high cutting passive forces generated during the milling process, if applied in low rigidity machine tools or in low rigidity fixture devices, can cause vibrations damaging the roughness of the machined surface.

It is also possible to see the small influence of cutting speed on surface finish quality, within the range of $\mathrm{v}_{\mathrm{c}}$ stipulated in the experimental design of this work.

Based on literature of machining technique, which determines the roughness depending on the cutting conditions and the results of the tests that showed the simple interaction of each one of the three cutting parameters adopted with the surface roughness of the machining process, a non linear regression was performed, through the software NLREG according to the equation:

$$
R_{a}=k \cdot v_{c}^{a} \cdot f_{z}^{b} \cdot a_{p}^{c}
$$

As a result of non linear regression, it was obtained the equation 2 below, that shows $\mathrm{R} 2=69,44 \%(\mathrm{R} 2 \mathrm{aj}=63,7 \%)$. Figure 4 shows the graph of surface roughness in terms of three cutting parameters extracted from the proposed equation:

$$
R_{a}=3,48 \cdot v_{c}^{-0.228} \cdot f_{z}^{0.320} \cdot a_{p}^{0.373}
$$

The residual stresses values listed in Table 3 represent the maximum value obtained of compressive residual stress in each specimen through the twenty measurements in the 0,4 $\mathrm{mm}$ drill performed (measurement in intervals of $20 \mu \mathrm{m}$ ) in the direction of feed per tooth $(\mathrm{X})$, or in the perpendicular direction to the feed per tooth (Y). In the same Table 3 is possible to observe a correlation between the resultant cutting forces and roughness as proposed by Mia, $\mathrm{Al}$ Bashir and Dhar ${ }^{20}$, where a strong relationship between cutting forces and roughness was observed during end milling, greater resultant cutting forces values with greater roughness values. Improved surface finish and lower cutting force can be attributed to the lower cutting temperature, favorable chip-tool interaction, retention of the cutting edge sharpness, as described by Al Bashir, Mia and Dhar ${ }^{21}$. 


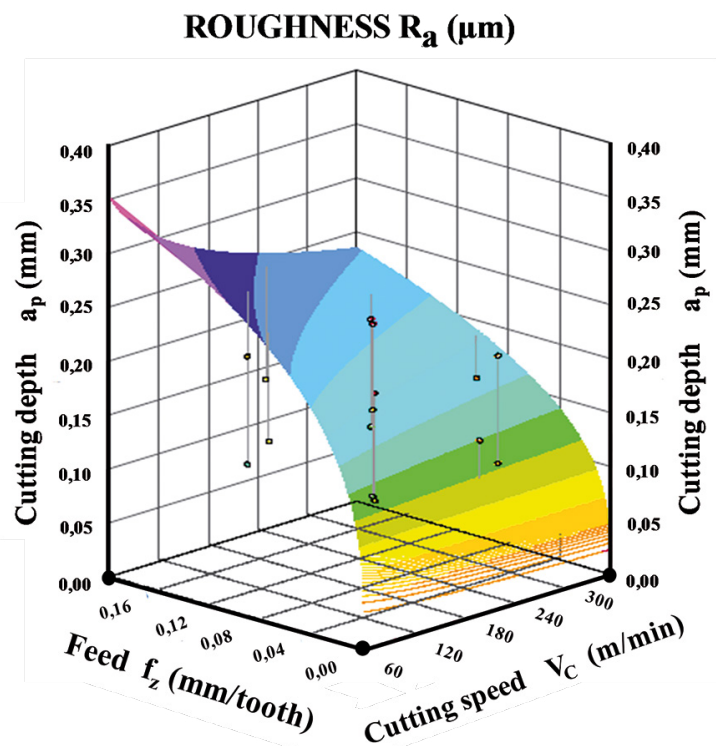

Figure 4. NLREG graphic, no linear relation of roughness vs. cutting parameters $\left(a_{p}, f_{z}\right.$ e $\left.v_{c}\right)$.

Table 3. Results for the residual stresses

\begin{tabular}{lccc}
\hline Test & $\begin{array}{c}\text { Resultant Cutting } \\
\text { Force }[\mathrm{N}]\end{array}$ & $\begin{array}{c}\text { Roughness } \\
{[\mathrm{um}]}\end{array}$ & $\begin{array}{c}\text { Residual Stress } \\
{[\mathrm{MPa}]}\end{array}$ \\
\hline 1 & 301 & 0,18 & -800 \\
2 & 429 & 0,19 & -800 \\
3 & 300 & 0,22 & -900 \\
4 & 481 & 0,41 & -850 \\
5 & 261 & 0,19 & -800 \\
6 & 344 & 0,25 & -1050 \\
7 & 391 & 0,25 & -950 \\
8 & 545 & 0,29 & -1050 \\
9 & 599 & 0,30 & -600 \\
10 & 524 & 0,19 & -1400 \\
11 & 149 & 0,16 & -500 \\
12 & 564 & 0,30 & -500 \\
13 & 237 & 0,20 & -1000 \\
14 & 387 & 0,25 & -1200 \\
$15^{\circ}$ & 376 & 0,21 & -1250 \\
$16^{\circ}$ & 441 & 0,24 & -1250 \\
$17^{\circ}$ & 407 & 0,25 & -1200 \\
$18^{\circ}$ & 412 & 0,23 & -1000 \\
$19^{\circ}$ & 408 & 0,22 & -1100 \\
$20^{\circ}$ & 424 & 0,23 & -1200 \\
\hline
\end{tabular}

The residual stress values $(\mathrm{X})$ and $(\mathrm{Y})$ assumed for each test were extracted from the chart behavior of residual stresses in $\mathrm{X}$ and $\mathrm{Y}$ axes as a function of depth from the surface of the blind hole, as shown in Figure 5, which represents the specimen 1.

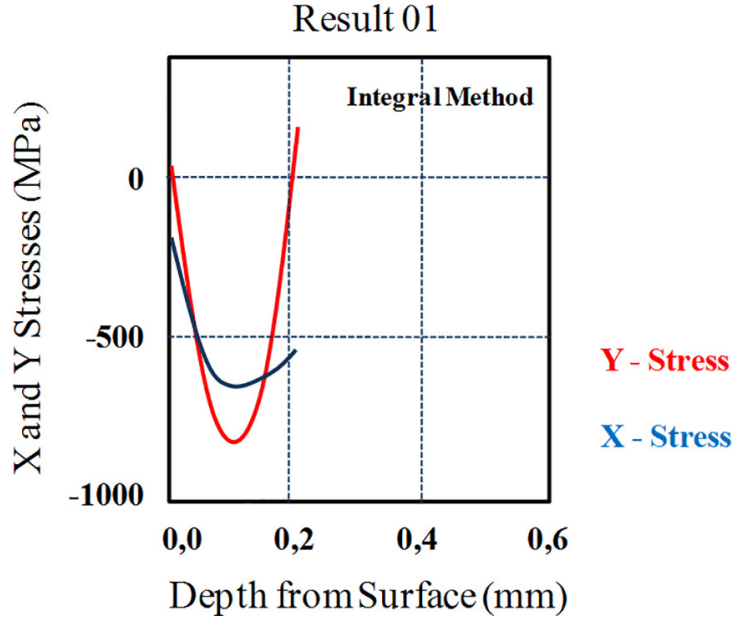

Figure 5. Residual stresses profile $\mathrm{X}$ and $\mathrm{Y}$ for the test 1

The samples tested showed compressive residual stresses located at depth 0,1 to $0,25 \mathrm{~mm}$ from the machined surface.

The compressive residual stresses encountered varied from $500 \mathrm{MPa}$ to $1400 \mathrm{MPa}$. The twelve specimens, unlike the others, already introduced compressive residual stress in the surface of the workpiece, in order of $350 \mathrm{MPa}$, and the maximum compressive stress of $500 \mathrm{MPa}$ that was obtained with $60 \mu \mathrm{m}$ below. If taken into consideration that the feed per tooth was the main parameter for the result of the residual stresses, and that in this specimen was used a feed per tooth of $0,183 \mathrm{~mm} /$ tooth, (hence the highest amount applied in twenty experiments), it is possible to understand why compressive stresses appeared in the piece surface, by the mechanical effect of plastic deformation, as confirmed by ${ }^{8}$ that obtained the same effect when analyzed surface residual stresses generated in the specimen of Inconel 718 machined by CBN inserts.

By the contour chart, characterized by Figure 6, which shows the behavior of residual stress due to the feed per tooth and cutting speed, it was found that the maximum residual stress occurred with the $\mathrm{v}_{\mathrm{c}}$ higher than $300 \mathrm{~m} / \mathrm{min}$ and $\mathrm{f}_{\mathrm{z}}$ medium to high.

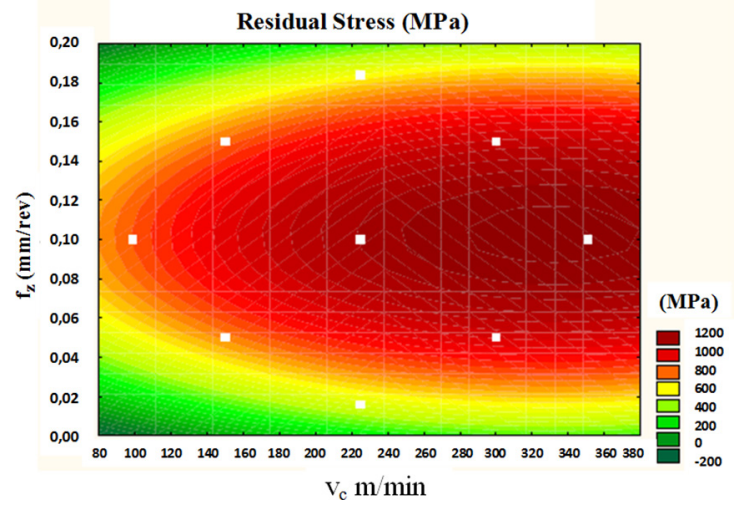

Figure 6: Countor chart $\left(f_{z} \times v_{c}\right)$ for the residual stress adopting $\mathrm{a}_{\mathrm{p}}=0,15 \mathrm{~mm}$ 
The contour chart illustrated in Figure 7 shows the behavior of the cutting depth $\left(a_{p}\right)$ relative to cutting speed, and shows that the cutting depth had a low interacted with the residual stresses. The influence has become clearer to medium and high cutting depths when combined with high cutting speed $\left(\mathrm{v}_{\mathrm{c}}\right)$, which caused high compressive residual stresses.

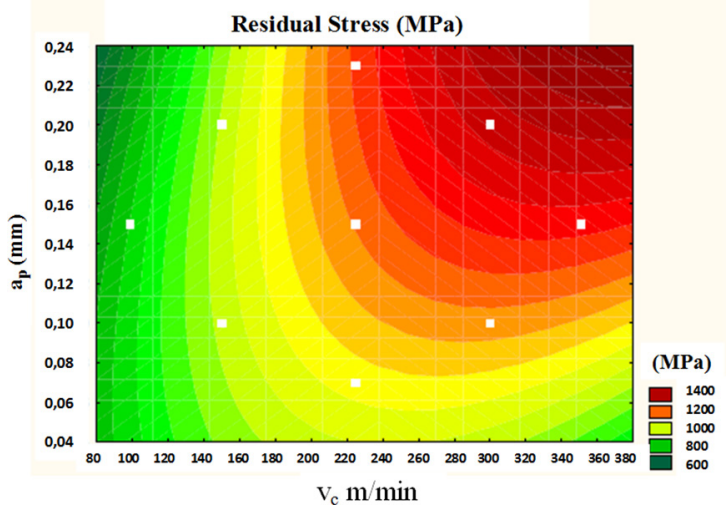

Figure 7: Countor chart $\left(a_{p} x_{c}\right)$ for the residual stress adopting $\mathrm{f}_{\mathrm{z}}=0,10 \mathrm{~mm} /$ tooth

Figure 8 represents the behavior of the feed per tooth as a function of the cutting depth, and it was found that $f_{z}$ interacted with the maximum compressive residual stresses obtained in the twenty specimens. Mean values of feed per tooth resulted in higher residual stresses.

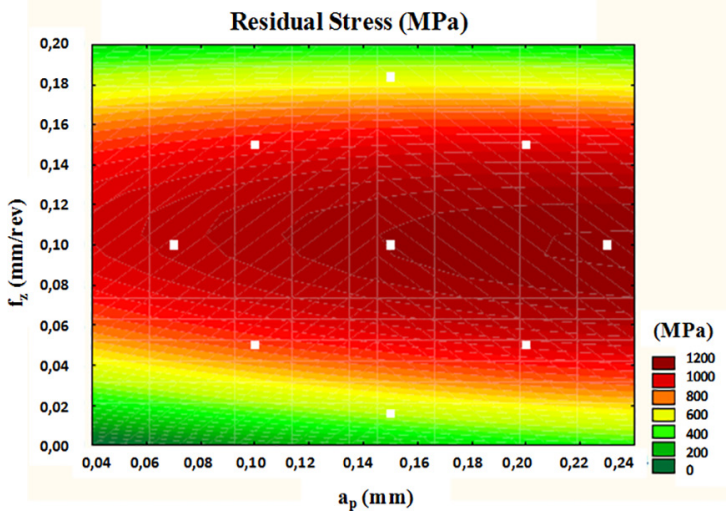

Figure 8. Countor chart $\left(a_{p} \times f_{z}\right)$ for the residual stress adopting $\mathrm{v}_{\mathrm{c}}=225 \mathrm{~m} / \mathrm{min}$.

The results of micrographs showed no formation of white layer on the surface of the specimens machined as shown in Figure 9. The surface structure shows tempered martensite, one of the characteristics of quenching and tempering treatment applied.

For many researchers, the white layer formation is associated with a requenching process caused by high cutting

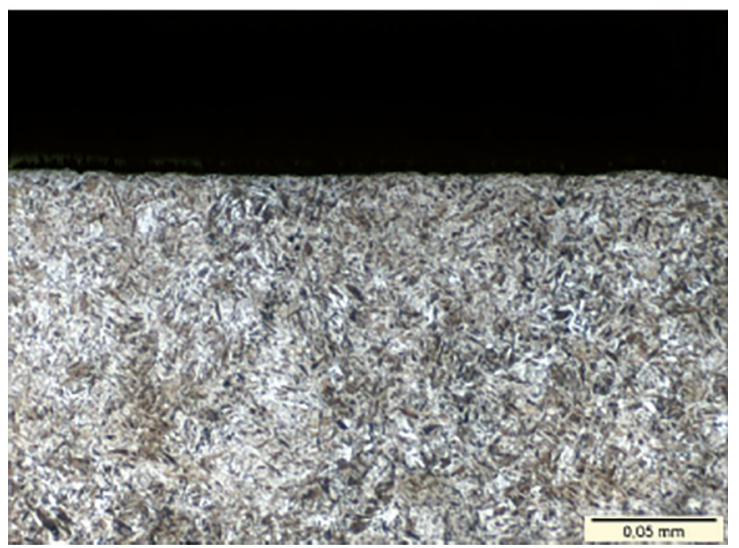

Figure 9. Micrography of spicemen 04 , magnification of 500x with Nital $2 \%$. Tempered martensite structure with no white layer formation.

temperature from the plastic flow of the material, or the use of cutting inserts quite worn, resulting in a homogeneous surface structure, thermally stable, with high hardness and brittle.

With the results, which showed a good interaction between the independent and the dependent variables, it was decided to simulate three scenarios combining the search for a piece with excellent performance, that means, surface optimized (minimum roughness and maximum compressive residual stress), with a machining process that prioritizes low cutting forces (minimizing the power consumption and vibrations transmitted to the machine), or a minimum time of machining, seeking a better productivity and probably lower cost.

The optimizations were done by the "Desirability" function from Statistica software version 10.0 which produced three surfaces responses as a function of all possible interactions generated by the adopted cutting parameters, by mathematical expressions associated with the roughness and residual stresses described as follows:

$$
\begin{aligned}
& R_{\mathrm{a}}=0,1-6,7 \times 10^{-5} \mathrm{v}_{c}+2 \times 10^{-6} \mathrm{v}_{c 2}+ \\
& 0,5 \mathrm{f}_{z}-1,3 \mathrm{f}_{\mathrm{z}}^{2}+0,2 \mathrm{a}_{p}+0,6 \mathrm{a}_{p}^{2}- \\
& 5 \times 10^{-3} \mathrm{v}_{c} \cdot \mathrm{f}_{\mathrm{z}}-3 \times 10^{-3} \mathrm{v}_{c} \cdot \mathrm{a}_{p}+8,1 \mathrm{f}_{z} \cdot \mathrm{a}_{p} \\
& T_{\text {res }}=570,2-3,6 \mathrm{v}_{c}-19925,6 \mathrm{f}_{z}+ \\
& 89931,1 \mathrm{f}_{z}^{2}-455,6 \mathrm{a}_{p}+5079 \mathrm{a}_{p}^{2}- \\
& 13,3 \mathrm{v}_{c} \cdot \mathrm{a}_{p}+10000 \mathrm{f}_{\mathrm{z}} \cdot \mathrm{a}_{p}
\end{aligned}
$$

Associating the absence of the white layer for some applications of AISI 4140, as rings for rolling tracks, probably will get a benefit to system operation, since the fragility of the white layer may accelerate the propagation of microcracks generated by milling process.

The first optimization aim to maintain the best condition of part performance (lower roughness and higher compressive residual stress), maximizing the component life, but in return 
the shortest time machining, by the pursuit of greater cutting forces $\mathrm{R}$, ignoring the $\mathrm{CBN}$ tool wear and increasing the power consumed by milling.

The input data in STATISTICA software for the "Desirability" aim to quantify: $\mathrm{R}_{\mathrm{a}}$ - minimal; $\mathrm{T}_{\text {res }}$ - maximum compressive, $\mathrm{R}$ - maximum. The input values optimized are: $\mathrm{v}_{\mathrm{c}}=351,1 \mathrm{~m} / \mathrm{min}, \mathrm{f}_{\mathrm{z}}=0,11 \mathrm{~mm} /$ tooth $\mathrm{a}_{\mathrm{p}}=0,18 \mathrm{~mm}$. The parameters of the component are: $\mathrm{R}_{\mathrm{a}}=0,24 \mathrm{um}$; Residual Stress $=-1327 \mathrm{MPa}$.

The second optimization aim to the shortest possible time machining, setting the maximum cutting forces $\mathrm{R}$, with the boundary condition of the part performance, that means, maximum acceptable values for the surface roughness and residual stress, which do not compromise the functioning and consequently the component life. The input data in STATISTICA software for the "Desirability" aim to: $\mathrm{R}_{\mathrm{a}}$ maximum (for working condition); $\mathrm{T}_{\text {res }}$ - minimum compressive residual stress (not to affect the fatigue life), $\mathrm{R}$ - maximum. The input values optimized are: $\mathrm{v}_{\mathrm{c}}=344,9 \mathrm{~m} / \mathrm{min}, \mathrm{f}_{\mathrm{z}}=0,17$ $\mathrm{mm} /$ tooth, $\mathrm{a}_{\mathrm{p}}=0,21 \mathrm{~mm}$. The parameters of the component are: $\mathrm{R}_{\mathrm{a}}=0,29 \mathrm{um}$; Residual Stress $=-931 \mathrm{MPa}$.

\section{Conclusions}

According to the different assumed values for the three cutting parameters adopted, it was found that there was an interaction of each one with studied cutting forces with greater relevance to the feed per tooth " $f$ ", followed by the cutting depth " $a_{p}$ ", and finally the cutting speed " $v_{c}$ ".

The roughness values $\mathrm{R}_{\mathrm{a}}$ ranged from 0,16 to $0,41 \mu \mathrm{m}$.

The roughness interacted with the feed per tooth and cutting depth, so that higher feed per tooth combined with higher cutting depth generated a worse surface finishing.

It was possible to establish a geometric expression relating, feed per tooth " $f_{z}$ ", cutting depth " $a_{p}$ " and cutting speed " $v_{c}$ " with the surface roughness using a nonlinear regression method.

Based on these results, it can be stated that the finishing milling of hardened steel with $\mathrm{CBN}$ tool without the presence of cutting fluid generates a surface finishing as good as those found by the grinding process, with the advantage of being faster and less aggressive to the environment by eliminating the cutting fluid.

All machined specimens showed compressive residual stress at a depth of 0,1 to $0,25 \mathrm{~mm}$ from the surface. The subsurface stresses were shown compressive ranging from $500 \mathrm{MPa}$ to $1400 \mathrm{MPa}$.

The feed per tooth " $f_{z}$ " and cutting speed " $v_{c}$ " influenced residual stress. In general, high feed per tooth and medium to high cutting speed resulted in higher intensity residual stresses.

On the surface measurements performed between 0 and $20 \mu \mathrm{m}$ showed none or minimal residual stresses compression.
The only exception occurred in the specimen twelve that, due to the high feed of $0,183 \mathrm{~mm} /$ tooth, already presented compressive surface stress of about $350 \mathrm{MPa}$.

It was not obtained white layer formation in any of the twenty specimens tested. This may be related to the range of the cutting parameters adopted in combination with small wear suffered by the $\mathrm{CBN}$ inserts. The inserts were changed three times during the test, thus avoiding the influence of the wear of the tool.

The material AISI4140 hardened and tempered with a hardness of $58 \pm 2 \mathrm{HRC}$ and depth of $3 \pm 1 \mathrm{~mm}$ when machined with $\mathrm{CBN}$ tool, proved to be adequate to generate low roughness surfaces through proper optimization of the three fundamental cutting parameters, with the following advantages:

a) compressive residual stresses at the component surface;

b) surface finishing compatible with grinding processes, with lower machining time;

c) disposal of cutting fluid.

\section{Acknowledgements}

The authors are grateful to the University Center of FEI.

\section{References}

1. Kalpakjian S. Manufacturing Engineering and Technology. $3^{\text {rd }}$ ed. Reading: Addison-Wesley; 1995. 1271 p

2. Mia M, Dhar NR. Optimization of surface roughness and cutting temperature in high-pressure coolant-assisted hard turning using Taguchi method. International Journal of Advanced Manufacturing Technology. 2016. DOI: 10.1007/s00170-0168810-2

3. Field M, Kahles JF. Review of surface integrity of machined components. CIRP Annals. 1971;20(2):153-163.

4. Griffiths B. Manufacturing Surface Technology. London: Penton Press; 2001. 237 p.

5. Deonisio CCC. Study of milling of hardened steel D2 with high speed cutting. [Thesis]. Campinas: State University of Campinas; 2004.

6. Mia M, Dhar NR. Prediction of surface roughness in hard turning under high pressure coolant using Artificial Neural Network. Measurement. 2016;92:464-474.

7. Smith S, Melkote SN, Lara-Curzio E, Watkins TR, Allard L, Riester L. Effect of surface integrity of hard turned AISI 52100 steel on fatigue performance. Materials Science and Engineering: A. 2007;459(1-2):337-346.

8. Arunachalan RM, Mannan MA, Spowage AC. Residual stress and surface roughness when facing age hardened Inconel 718 with CBN and ceramic cutting tools. International Journal of Machine Tools and Manufacture. 2004;44(9):879-887.

9. El-Khabeery MM, Fattouh M. Residual stress distribution caused by milling. International Journal of Machine Tools and Manufacture. 1989;29(3):391-401. 
10. Lu J; Society for Experimental Mechanics. Handbook of Measurement of Residual Stresses. $1^{\text {st }}$ ed. Lilburn: Fairmont Press; 1996.

11. Soares MCBV. Influence of residual stresses on fatigue and fracture behaviour of metallic alloys. [Thesis]. São Paulo: Institute of Energetic and Nuclear Research (IPEN); 1998.

12. Damasceno D. Análise das tensões residuais após torneamento e retificação do aço ABNT 52100 endurecido. [Dissertation]. Campinas: State University of Campinas, Campinas, 1993.

13. Jawahir IS, Brinksmeier E, M'Saoubi R, Aspinwall DK, Outeiro JC, Meyer D, et al. Surface integrity in material removal processes: Recent advances. CIRP Annals - Manufacturing Technology. 2011;60(2):603-626.

14. da Silva LR, Bianchi EC, Fusse RY, Catai RE, França TV, Aguiar PR. Analisys of surface integrity for minimum quantity lubricant-MQL in grinding. International Journal of Machine Tools and Manufacture. 2007;47(2):412-418.

15. Mhamdi MB, Boujelbene M, Bayraktar E, Zghal A. Surface Integrity of Titanium Alloy Ti-6A14V in Ball end Milling. Physics Procedia. 2012;25:355-362.
16. Umbrello D, Micari F, Jawahir IS. The effects of cryogenic cooling on surface integrity in hard machining: A comparison with dry machining. CIRP Annals - Manufacturing Technology. 2012;61(1):103-106.

17. Pusavec F, Hamdi H, Kopac J, Jawahir IS. Surface integrity in cryogenic machining of nickel based alloy-Inconel 718. Journal of Materials Processing Technology. 2011;211(4):773-783.

18. Klocke F, Gierlings S, Brockmann M, Veselovac D. Influence of Temperature on Surface Integrity for Typical Machining Processes in Aero Engine Manufacture. Procedia Engineering. 2011;19:203-208.

19. Li W, Guo Y, Guo C. Superior surface integrity by sustainable dry hard milling and impact on fatigue. CIRP Annals - Manufacturing Technology. 2013;62(1):567-570.

20. Mia M, Al Bashir M, Khan MA, Dhar NR. Optimization of MQL flow rate for minimum cutting force and surface roughness in end milling of hardened steel (HRC 40). International Journal of Advanced Manufacturing Technology. 2016. DOI: 10.1007/s00170-016-9080-8

21. Al Bashir M, Mia M, Dhar NR. Investigations on Surface Milling of Hardened AISI 4140 Steel with Pulse Jet MQL Applicator. Journal of the Institution of Engineers (India): Series C. 2016. DOI: $10.1007 / \mathrm{s} 40032-016-0277-2$ 